\title{
Neumonía causada por Corynebacterium pseudodiphteriticum; una entidad a conocer
}

\author{
C. ASPIROZ SANCHO, A. AGUSTÍN BERNE*, C. NAVARRO PARDOS, \\ B. SAÑUDO BLASCO*, P. TELLER JUSTES** \\ Servicios de Microbiología, *Medicina Interna y **Neumología. Hospital de Alcañiz. \\ Teruel
}

\author{
PNEUMONIA CAUSED BY CORYNEBACTERIUM \\ PSEUDODIPHTERITICUM
}

\begin{abstract}
RESUMEN
El estudio de infecciones con significado clínico originadas por bacterias de patogenicidad poco conocida, nos lleva a presentar el siguiente caso que tiene como protagonista a una de estas especies, Corynebacterium pseudodiphteriticum. Este microorganismo forma parte de la flora bacteriana orofaríngea y por lo tanto se relaciona principalmente con patología respiratoria, pero también se han descrito casos de endocarditis, infecciones de prótesis y heridas. El caso que nos ocupa refiere una neumonía nosocomial que asienta en una paciente varón de 75 años, entre cuyos antecedentes personales resaltan los de ser fumador importante y padecer EPOC. El diagnóstico microbiológico consistió en el cultivo del broncoaspirado, en el que se observó una importante reacción leucocitaria, con bacilos gram-positivo intra y extracelulares, y del que se aisló C. pseudodiptheriticum en cultivo puro. Se comenzó el tratamiento con cefotaxima, y el paciente evolucionó favorablemente, con resolución clínica y radiológica de su neumonía.
\end{abstract}

PALABRAS CLAVE: Corinebacterias. Neumonía. Corynebacterium pseudodiphteriticum.

\begin{abstract}
Respiratory infections are challenging for clinicians and new micro bes or those considered previously as normal flora or less virulent forms seen responsible for some cases. Thus, the case reported here is a noso comial pneumonia caused by Corynebacterium pseudodiphteriticum in a man suffering chronic obstructive pulmonary disease and resolved with cefotaxime. This microorganism is part of the oropharingeal bacterial flora and is therefore associated mainly with respiratory disease an less commonly with endocarditis, prostheses or wound infections. Susceptibi lity testing found uniform susceptibility to b-lactamases, aminoglycosi des, rifampin and tetracycline. Susceptibility to ciprofloxacine is varia ble and resistance to macrolides (erythromycin and clindamycin) was frequent.
\end{abstract}

KEY WORDS: Diphteroids. Corinebacteria. Pneumonia. Corynebacte rium pseudodiphteriticum.

Aspiroz Sancho C, Agustín Berne A, Navarro Pardos C, Sañudo Blasco B, Teller Justes P. Neumonía por Corynebacterium pseudodiphteriticum. An Med Interna (Madrid) 2002; 19: 463-465.

\section{INTRODUCCIÓN}

Es llamativo el aumento de incidencia de infecciones con significado clínico causadas por bacterias consideradas clásicamente como comensales o bien de patogenicidad poco conocida. Uno de los casos más llamativos es el que concierne a las llamadas bacterias "corineformes" o "difteroides", términos empleados para denominar a aquellos microorganismos gram-positivos similares morfológicamente a Corynebacte rium diphteriae. Dentro de este amplio grupo se han documentado casos de endocarditis, osteomielitis, peritonitis, infecciones urinarias, sepsis, infecciones de heridas o abscesos (1). Así, gracias a los avances taxonómicos y a la cuidadosa valoración del significado clínico de los aislamientos humanos de estas bacterias, se está alcanzando una mejor comprensión de unos organismos que tradicionalmente han sido considerados como contaminantes o colonizadores no patógenos (2).

El caso que se presenta tiene como protagonista a una de estas especies conocida como C. pseudodiphteriticum. Este microorganismo forma parte de la flora bacteriana orofaríngea y por lo tanto se relaciona principalmente con patología respiratoria, aunque también puede causar endocarditis, infecciones de prótesis y heridas e incluso lesiones cutáneas $(1,3,4)$. La mayoría de los casos publicados relacionados con esta bacteria se han documentado en personas inmunodeprimidas (57 ), aunque puede también causar neumonía o bronquititis en personas inmunocompetentes (8-11). Dentro de la patología

Trabajo aceptado: 9 de marzo de 2001

Correspondencia: Carmen Aspíroz. Servicio de Microbiología. Hospital Royo Villanova. Avda. San Gregorio, 30.50015. Zaragoza. Fax: 97646 69 18. e-mail:beagle@ctv.es 
respiratoria, es relativamente frecuente en pacientes intubados (con la consiguiente posibilidad de introducción de estas corinebacterias de hábitat orofaríngeo hacia el tracto respiratorio inferior) o bien con trastornos en el reflejo tusígeno. Radiográficamente se ha descrito la presencia de infiltrados alveolares, cavitación y derrame pleural. Es frecuente el aislamiento de este patógeno respiratorio en muestras de aspirado bronquial, como en el presente caso (5).

C. pseudodiphteriticum está incluida dentro de las corinebacterias no fermentadoras y no lipofílicas (1), y en los estudios de sensibilidad antimicrobiana muestra una susceptibilidad generalizada a los betalactámicos, aminoglicósidos, rifampicina y tetraciclina, con sensibilidad variable a quinolonas (ciprofloxacino) y con frecuentes resistencias en lo que respecta a los macrólidos (eritromicina y clindamicina) $(6,9)$.

\section{CASO APORTADO}

Varón de 75 años con antecedentes personales de accidente cerebrovascular y EPOC en tratamiento habitual con bromuro de ipatropio, terbutalina y budesonida. Fumador de aproximadamente 40 paquetes de cigarrillos/año. Ingresa en nuestro centro por aumento de su disnea, sin otros síntomas. Hacía diez días había sido dado de alta en el mismo centro hospitalario, donde había sido tratado de pleuroneumonía basal izda y neumonía en lóbulo inferior derecho, presentando como complicación en su evolución un neumotórax tras toracocentesis diagnóstica (Fig.1). En la exploración física actual destacaba: paciente afebril, tensión arterial 120/60, frecuencia cardíaca a 100 por minuto, sin taquipnea. En la auscultación pulmonar se percibieron crepitantes en base pulmonar izquierda y roncus aislados. Presentaba edemas en las extremidades inferiores. Entre las pruebas complementarias destacaba en la radiografia de tórax: consolidación pleuroparenquimatosa en lóbulo inferior izquierdo e hiperinsuflación pulmonar. En la analítica de ingreso destacamos: glucosa $250 \mathrm{mg} / \mathrm{dl}, \mathrm{Hb} 12,3 \mathrm{~g} / \mathrm{dl}$, Hto 37\%, VCM 89,3 fl, HCM 29,6 pg, leucocitosis $\left(1,2 \times 10^{9}\right)$ con neutrofilia $(93,4 \%)$, VSG $107 \mathrm{~mm}$. Gasometria de ingreso: $\mathrm{pCO}^{2} 37,3 \mathrm{mmHg}, \mathrm{pO}^{2} 50 \mathrm{mmHg}$, Saturación $\mathrm{O}^{2}$ $86,2 \%$; Se reinició tratamiento con fluidoterapia, broncodilatadores inhalados, corticoides, ceftriaxona, claritromicina, antihipertensivo y protección gástrica. A los cuatro días de este segundo ingreso, el paciente presentó un flutter auricular por lo cual se le administró digoxina, calcioantagonistas y acenocumarol, descendiendo la fre-

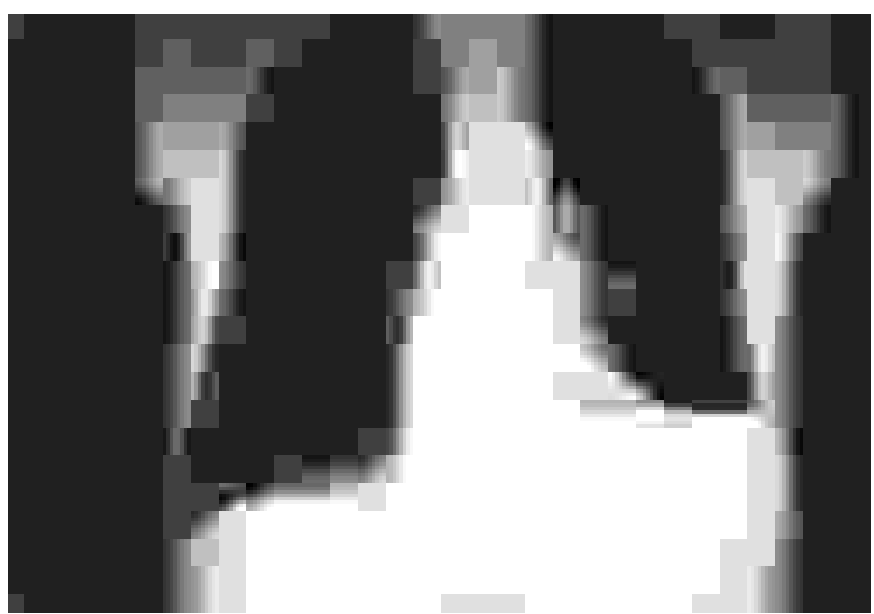

Fig. 1. Pleuroneumonía basal izda y neumonía en lóbulo inferior derecho. Se evidencia el neumotórax que apareció como complicación tras toracocentesis diagnóstica (RX correspondiente al primer ingreso). cuencia cardiaca a valores normales. Ante la decisión de realizar fibrobroncoscopia se suspendió temporalmente el tratamiento anticoagulante, sustituyéndose por heparina de bajo peso molecular. El informe de la fibrobroncoscopia -realizada a las dos semanas del ingreso- destacaba en árbol bronquial derecho signos de broncopatía crónica con secreciones mucosas. En árbol bronquial izquierdo asimismo se observaron y aspiraron abundantes secreciones mucosas. Se observó un ensanchamiento carinal BLS-BLI, que se biopsió y cepilló. No se encontraron masas ni estenosis bronquiales. El estudio anatomopatológico no evidenció malignidad. Tras la realización de la broncoscopia, se reinició el tratamiento con acenocumarol, continuando con el ciclo de antibióticos pautado, manteniéndose el paciente afebril y hemodinámicamente estable. Se planteó dar el alta hospitalaria, pero ese mismo día el paciente debutó con febrícula y esputo purulento. La fiebre fue aumentando progresivamente, con picos febriles superiores a $39^{\circ} \mathrm{C}$. La RX de tórax mostró consolidación pleuroparenquimatosa en lóbulo inferior izquierdo con derrame pleural izquierdo e hiperinsuflación pulmonar (Fig. 2). Se consultó con el laboratorio de Microbiología, que informó el crecimiento de C. pseudodiptheriticum en cultivo puro, procedente del broncoaspirado. La tinción de Ziehl-Neelsen fue negativa, y la tinción de gram evidenciaba una gran respuesta inflamatoria (>25 LMN/c x100) y gran cantidad de bacilos gram-positivo, intraleucocitarios y extracelulares. Ante el empeoramiento del cuadro clínico y el informe recibido, se comenzó el tratamiento con cefotaxima ( 3 g/día). La mejoría del paciente fue gradual y, pese a presentar varios picos febriles en los primeros días, evolucionó favorablemente tanto clínica como radiográficamente, por lo que fue dado de alta con el diagnóstico de neumonía por $C$. pseudodiphteriticum. En una revisión posterior el paciente se encontraba asintomático, y la RX de tórax evidenciaba una resolución del cuadro respiratorio.

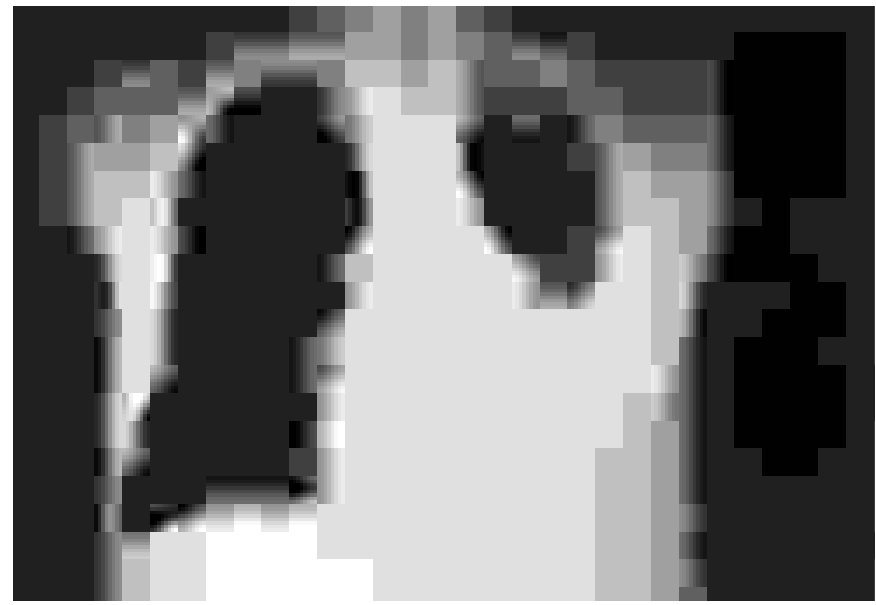

Fig. 2. RX en proyección PA de tórax del paciente, dónde se evidencia la consolidación pleuroparenquimatosa en lóbulo inferior izquierdo con derrame pleural izquierdo e hiperinsuflación pulmonar (RX correspondiente al caso presentado).

\section{DISCUSIÓN}

Pensamos que el caso presentado cumple los requerimientos microbiológicos necesarios para ser considerado un aislamiento significativo y el agente causal del cuadro clínico. Así, la tinción de gram del aspirado bronquial mostraba intensa reacción leucocitaria, y la única flora observada (intra y extracelularmente) estaba constituida por bacilos gram-positivo regulares. El cultivo en medios habituales (agar sangre y agar chocolate) mostró un aislamiento abundante y en cultivo puro 
de unas colonias -sensibles a la optoquina- que fenotípica y bioquímicamente se correspondían con $C$. pseudodiphteriti cum (1). Este caso describe una neumonía nosocomial por $C$. pseudodiphteriticum, infección documentada en contados casos, pues la mayoría de procesos son adquiridos en la comunidad y en pacientes con enfermedades de base o inmunodeprimidos (12). Podemos especular acerca de la adquisición de este microrganismo, que quizá fuera propiciado por la intervención yatrógena que motivó el neumotórax tras la toracocentesis, pues aunque su hábitat es preferentemente orofaríngeo, -y su mecanismo de entrada es con frecuencia por inhalación-, también puede encontrarse formando parte de la flora cutánea, desde dónde pudo introducirse en el árbol respiratorio. Por otro lado, se ha comentado que este tipo de infecciones cuando se presentan en pacientes no inmunocomprometidos, lo suelen hacer en aquellos con patología pulmonar previa, condición que presentaba el paciente y que se vio agravada por el proceso neumónico previo y por las complicaciones que propició la toracocentesis. El perfil de sensibilidad que ofrece $C$. pseudodiphteriticum es bastante constante, con sensibilidad in vitro a los betalactámicos, frecuente resistencia a los macrólidos y un grado variable de sensibilidad a las quinolonas, lo que para algunos autores las hace desaconsejables $(6,9)$. Nuestro aislamiento se mantuvo fiel a este patrón, siendo únicamente resistente a macrólidos (el paciente había recibido claritromicina), y presentando una excelente respuesta a la administración de cefotaxima.

Por último, insistimos en valorar cuidadosamente aquellos aislamientos de microorganismos clásicamente considerados como comensales, siempre que cumplan los criterios clínicos y microbiológicos pertinentes para poder ser interpretados como el agente etiológico del cuadro infeccioso.

\section{Bibliografía}

1. Funke G, von Graevenitz A, Clarridge III JE, Bernard KA. Clinical Microbiology of coryneform bacteria. Clin Microbiol Rev 1997; 10: 125-59.

2. Reynolds HY. Respiratory infections; community-acquired pneumonia and newer microbes. Lung 1996; 174: 207-24.

3. Morris A, Guild I. Endocarditis due to Corynebacterium pseudodiphte riticum: five case reports, review, and antibiotic susceptibilities of nine strains. Rev Infect Dis 1991; 13: 887-92.

4. Hemsley C, Abraham S, Rowland-Jones S. Corynebacterium pseudo diphteriticum. A skin pathogen. Clin Infect Dis 1999; 29: 938-9.

5. Cohen Y, Force G, Gros Y, Canzi AM, Lecleach L, Dreyfuss D. Cory nebacterium pseudodiphteriticum pulmonary infection in AIDS patients. Lancet 1992; 340: 114-5.

6. Roig P, Lopez MM, Arriero JM, Cuadrado JM, Martin C. Neumonía por Corynebacterium pseudodiphteriticum en un paciente con infección VIH. An Med Interna 1993; 10: 499-500.

7. Gutiérrez-Rodero F, Ortiz de la Tabla V, Martínez C, et al. Corynebac -

terium pseudodiphteriticum: an easily missed respiratory pathogen in HIV-infected patients. Diagn Microbiol Infect Dis 1993; 33: 209-16.

8. Ahmed K, Kawakami K, Watanabe K, Mitsushima H, Nagatake T, Matsumoto K. Corynebacterium pseudodiphteriticum: a respiratory tract pathogen. Clin Infect Dis 1995; 20: 41-6.

9. Manzella JP, Kellogg JA, Parsey KS. Corynebacterium pseudodiphteri ticum: a respiratory tract pathogen in adults. Clin Infect Dis 1995; 20: $37-40$.

10. Gorricho J, Villuendas MC, Remacha MA, Seoane A. Neumonía por Corynebacterium pseudodiphteriticum. Enf Infecc Microbiol Clin 1996; 14: 632-3.

11. Chiner E, Arriero JM, Signes-Costa J, et al. Corynebacterium pseudo diphteriticum pneumonia in an immunocompetent patient. Monaldi Arch Chest Dis 1999; 54: 325-7.

12. Martaresche C, Fournier PE, Jacomo V, Gainnier M, Boussuge A, Drancourt M. A case of Corynebacterium pseudodiphteriticum nosocomial pneumonia. Emerg Infect Dis 1999; 5: 722-3. 